ARTIGOS

\title{
A ESCRITURA TRADUTORA DE ALEJANDRA PIZARNIK
}

\author{
Fernanda Ribeiro Marra \\ Universidade de Brasília, Brasil \\ dizamarra@gmail.com \\ DOI: https://doi.org/10.26512/caleidoscopio.v1i1
}

RESUM0: Este artigo é uma proposta de tradução da escrita poética de Alejandra Pizarnik para a língua portuguesa. Trata-se de um trabalho preliminar ao ato mesmo da tradução que teria por finalidade última a operação da letra, no sentido da expressão entabulada por Haroldo de Campos, dos textos de Pizarnik. 0 objetivo é mostrar por onde passa a leitura que proponho dessa escritura, a relação inextrincável que vejo entre a literatura e a vida da autora, tal como se apresenta em seus poemas e diários. Além disso, busco justificar porque o projeto de tradução não só não pode prescindir da leitura detida do projeto de escritura da autora, como surge em decorrência dela.

Palavras-chave: Alejandra Pizarnik, poesia, escrita íntima, tradução.

\section{LA ESCRITURA TRADUCTORA DE ALEJANDRA PIZARNIK}

RESUMEN: Este trabajo presenta una propuesta de traducción de la escrita poética de Alejandra Pizarnik a la lengua portuguesa. Es un trabajo preliminar al acto de traducción que tiene por objetivo final la operación de la letra, en el sentido de la expresión usada por Haroldo de Campos, de los textos de Pizarnik. El objetivo es presentar los caminos por donde pasan la lectura de esa escritura, la relación inextricable que veo entre la literatura y la vida de esa autora, tal como se ofrece en sus poemas y diarios. Además, pretendo justificar el motivo por el cual el proyecto 
de traducción no solo no puede prescindir de la lectura detenida del proyecto de escritura de la poeta, sino que resulta de ella.

Palabras-claves: Alejandra Pizarnik, poesía, escrita íntima, traducción.

Alejandra Pizarnik é poeta argentina que viveu entre 1936 e 1972 . Tomar conhecimento dessa escritura teve sobre mim o efeito de uma convocação, que me impulsionou a estudá-la propondo um projeto de pesquisa de doutorado em teoria literária ${ }^{1}$ acerca dessa literatura. Constatei, durante a fase de elaboração do projeto, que se trata de uma literatura ainda pouco abordada pela crítica literária brasileira e me deparei com a falta de tradução e a escassa produção crítica acerca dos textos em língua portuguesa. Trabalhando na pesquisa, conforme leio e estudo os textos de Pizarnik, um desejo ganha força e assume a forma de outro chamado: traduzir os poemas de Alejandra Pizarnik para o português. Um longo percurso se desenha no processo desafiador de ler a poeta na obliquidade ${ }^{2}$ que é a relação entre seus poemas e seus diários. Em outros termos, na relação oblíqua entre literatura e vida. Porém, as naturezas desse duplo chamado me parecem cada vez menos distintas, sobretudo após ter lido a entrada do diário de 11 de abril do ano de 1963, em que a autora afirma que, em seu caso, escrever é traduzir ${ }^{3}$.

É daí de onde parto: desse enunciado que condensa um projeto de escritura e que pressupõe uma anterioridade ao ato da escrita. Se escrever é traduzir, só posso supor que haja algo antes dessa escrita, algo que a autora vê a necessidade de fazer entrar na linguagem, de nomear. A pergunta que sucede ao enunciado é: o que é,

\footnotetext{
10 presente artigo apresenta resultados preliminares de minha pesquisa de doutorado em andamento no âmbito dos estudos literários que se desenvolve em estreito diálogo com estudos semióticos e de tradução.

2 Bárbara Smith (1971) estabelece uma distinção entre enunciados naturais e enunciados fictícios, sendo que, nos primeiros, o sentido (do enunciado) está inextricavelmente relacionado ao contexto em que foram produzidos e que seguem sendo lidos. Os enunciados fictícios, porém, são da ordem da inventividade, da criação, da virtualidade e não necessariamente sustentam essa relação intrínseca com a história. No entanto, atravessam-na e fazem furo nessa dimensão temporal na medida em que o, ao produzir o enunciado, conta com determinadas convenções partilhadas pela comunidade cultural e linguística, que será capaz de inferir e projetar um contexto para aquele texto (p. 279). É assim que o texto literário (quase) acontece: no espaçamento desse atravessamento temporal, nessa obliquidade em que tangenciam e quase coincidem as instâncias discursivas (os corpos de autor, personagens, narrador, eu-lírico, leitor) no ato da leitura.

3 PIZARNIK, 2012, p. 331.
} 
então, que ela traduz? Creio que seja a isso que ela responde com sua literatura e que seja também o que devo ter em vista para me pronunciar sobre sua escritura. No caso dessa escritura tradutora, a nomeação é inerente à tradução, pois se trata de expressar, em uma língua de natureza conceitual, algo que não estaria diretamente perceptível na linguagem, ou que existiria preliminarmente para Pizarnik como "imagens visuais acompanhas de umas poucas palavras soltas" 4 . Algo da ordem do inexpresso, do impossível, que ela, todavia, porta, ouve, vê e sente a necessidade de simbolizar.

Outra pergunta seria: como traduzir o impossível, se para traduzir é necessária uma língua que, independentemente de qual seja, torna presente uma ausência? Alejandra tem absoluta ciência de que uma língua é representação e não coincide com o sem-nome que ela precisa expulsar de si por meio da ex-crita:

[...] todo tiene nombre pero el nombre no coincide con la cosa a la que me refiero. El lenguaje es un desafío para mi, un muro, algo que me expulsa, que me deja afuera. Nunca he pensado con frases. Apenas unas pocas palabras que zumban desde mi infancia. ${ }^{5}$

Nem por isso deixa de se aborrecer com esse contratempo: "Estoy cansada de mis aproximaciones, de mis tanteos. El abismo está. Es seguro. Te espera. Ya estás en él"' Sabe ainda que não se ex-creve com a ausência inerente a toda língua, pois o que precisa ser nomeado é a ausência mesma, o abismo. Creio ser isso o que ela diz literariamente com uma sintaxe que lhe é própria, que inventa a partir das línguas de que dispõe e que a constituem, por meio do esforço extenuante e fatal de dizer o impossível.

Diante dessa ideia de escritura, atento para a relação intrínseca entre literatura e vida. A natureza do que Alejandra Pizarnik produzirá será de caráter vital e apriorístico, como é a natureza da poesia. Sua escritura é indecidivelmente o que a sustenta e o que a aniquila. Assim, entendo que só é possível pensar um projeto de tradução para essa autora que interprete sua produção literária preservando as

\footnotetext{
4 Ibid., p. 331.

5 Ibid., p. 286.

${ }^{6}$ Ibid., p. 279.
} 
pontes da imanência que interligam a arte e a vida. Coincido com Haroldo de Campos $^{7}$ quando sustenta que a crítica literária passa pela operação do texto como uma experiência de tradução, ainda que intralinguística, e que a experiência tradutória não pode prescindir do exercício árduo de leitura e interpretação do projeto autoral que se traduz. Ademais, projeto em meu exercício crítico essa intenção, de que também falou Campos $^{8}$, de preservar a função transgressora e diferencial da obra literária, pois é isso o que possibilita a loquacidade da ruptura, da descontinuidade. É nesse exercício de ouvir - não a voz do logos, mas da diferença - que vai se tornando possível localizar a gratuidade (outro termo usado por Campos), isto é, o aspecto espontâneo e genuíno da obra que não se explica pelo compromisso com a continuidade do sistema literário, senão pelo engajamento do autor com o envio de sua letra.

Operar é intervir, trabalhar, propor uma ordem. 0 tradutor opera o texto. A tradução literária depende do estudo crítico da obra para proceder às escolhas na linguagem construída pela tradução que melhor se aproximem das escolhas do autor traduzido. Por outro lado, a tradução possibilita à crítica enveredar por aspectos linguísticos do texto que conferem amplitude ao horizonte da disseminação. Creio que seja isso o que Campos demonstra nos ensaios de $A$ operação do texto em que apresenta suas escolhas tradutórias para diferentes textos e autores justificando cada uma delas. 0 crítico e tradutor escolhe com a responsabilidade de quem assume os riscos pelas alterações que os procedimentos cirúrgicos de uma tradução podem causar ao corpo do texto, à sua materialidade. E, por mais que se sinta autorizado a comutar a letra, não perde de vista o compromisso com o projeto de escritura do autor traduzido.

Elizabeth Muylaert Duque-Estrada ${ }^{9}$ refletindo acerca da relação entre a filosofia derridiana e a literatura, perora que o esforço de distinguir o "espaço próprio à efetividade da vida" do "espaço próprio à obra" não é um movimento natural, tendo em vista que os limites entre um espaço e outro não existem a priori e qualquer tentativa de estabelecê-los configura uma construção. Acrescentaria que,

\footnotetext{
${ }^{7}$ CAMPOS, 1976.

${ }^{8}$ CAMPOS, 2011, p. 65.

${ }^{9}$ DUQUE-ESTRADA, 2014, p. 91.
} 
quando proponho um projeto de tradução de um autor e elejo aspectos de sua escritura para desenvolver argumentos sobre minha leitura, isso não deixa de ser também uma construção. Todavia, uma construção consciente da permeabilidade dos limites entre os espaços da literatura e da vida, isto é, a evidenciação do espaçamento, do entre, do talvez. Importa destacar que em termos pizarnikianos, a poesia acontece precisamente nesse lugar do entre:

La poesía, no como substitución, sino como creación de una realidad independiente - dentro de lo posible - de la realidad a que estoy acostumbrada. Las imágenes solas no emocionan, deben ir referidas a nuestra herida: la vida, la muerte, el amor, el deseo, la angustia. Nombrar nuestra herida sin arrastrarla a un proceso de alquimia en virtud del cual consigue alas, es vulgar. ${ }^{10}$

Assim, passo ao meu projeto de tradução da obra de Pizarnik explicitando eixos que guiam minha leitura acerca de sua escritura. Para isso, apresento brevemente a narrativa das condições da origem de Pizarnik para que fique evidenciada desde já a relação intrínseca entre sua escritura e sua vida.

Alejandra é filha de imigrantes russos-judios que em 1934 chegaram da Europa na Argentina. Seus pais eram de Rovne, na Europa Oriental, e se estabeleceram em Buenos Aires, no bairro de Avellaneda, onde já havia uma comunidade judia e começariam uma vida familiar longe do devastado cenário europeu da Primeira Guerra Mundial. Em Buenos Aires, nasceram e cresceram Flora Alejandra e Myriam, sua irmã mais velha. A biógrafa, Cristina Piña ${ }^{11}$ conta que - a não ser pelos tios paternos de Pizarnik que viviam em Paris e ofereceram abrigo a Elias e Rosa meses antes de se mudarem para Argentina - as famílias de ambos haviam sido aniquiladas pelos efeitos da Guerra.

Observo que desde o início da narrativa sobre a vida de Pizarnik a qualidade de estrangeira está presente, essa origem imigrante da família precede inclusive o seu nascimento. Dois anos separam a chegada de seus pais na Argentina de sua vinda ao mundo. Sua infância aconteceu na comunidade judia frequentando duas escolas: a Escuela no 7 de Avellaneda, para aprender espanhol e se integrar à vida e à cultura

${ }^{10}$ PIZARNIK, 2012, p. 79.

11 PIÑA, 1999. 
da cidade onde foram viver, e a outra, a Zalman Reizien Schule, onde ensinavam a ler e escrever yiddish com vistas a instruir sobre a história do povo judeu e as tradições religiosas judaicas. Tudo isso marca a vinda de Flora Alejandra ao mundo e forja sua singularidade na maneira como lidou com esses aspectos contingentes que atravessaram sua vida.

Além das escolas, das culturas, da religião, dos continentes e das línguas, atento para a questão do nome dessa menina judia que, a meu ver, ultrapassa em muito a mera curiosidade. Seu nome, composto de batismo, como já apresentei, era Flora Alejandra. Porém, durante toda a infância fora chamada pelo primeiro nome, ou pelas variações a que ele se prestava nessa remissão bilíngue ao mundo das flores: Flora, na Escola № 7; em sua casa e entre as amigas, Buma, o correspondente yiddish para Flora ou Flor e que se transformava no diminutivo Blímele com que a chamavam na escola judia, e, por fim, Bumita, apelido carinhoso dado por seus pais. Acerca da nomeação, provém da leitura filosófica de outro judeu, Jacques Derrida ${ }^{12}$, a noção de que receber um nome é submeter-se, sem que disso decorra uma alternativa, a uma passividade que implica na impossibilidade de se reapropriar do próprio nome. Dessa passividade, adviria uma tristeza pelo fato de que o nome sobrevive ao nomeado e de que, a cada reiteração, traz a ele a notícia de uma morte por vir:

\footnotetext{
Aquele que recebe um nome sente-se mortal ou morrendo, justamente porque o nome quereria salvá-lo, chamá-lo e assegurar sua sobrevivência. Ser chamado, escutar-se nomear, receber um nome pela primeira vez, é talvez saber-se mortal e ao mesmo tempo sentir-se morrer. Já morto por estar prometido à morte: morrendo. ${ }^{13}$
}

Na primeira adolescência, todavia, as coisas começaram a mudar em relação a esses tantos nomes pelos quais Pizarnik é chamada. Em determinado momento de sua vida - segundo a biógrafa, antes de entrar para a faculdade - Pizarnik teria passado a assumir o seu segundo nome, Alejandra, pedindo a todos que assim a chamassem. Se a reapropriação era impossível, algum âmbito de escolha coube à

\footnotetext{
12 DERRIDA, 2011.

${ }^{13} \mathrm{Ibid}$, p. $42-43$.
} 
poeta nesse momento em que assumiu o nome com que assinou sua literatura, o nome dado a ela e pelo qual não atendia porque não era chamada. Contudo, é ao chamado desse nome que Pizarnik deseja responder e é com ele que passará a nomear o testemunho de experiência singular que é ser Alejandra, que é haver recebido esse nome e ter a responsabilidade de portá-lo respondendo ao seu chamado.

O verbo alejar, em espanhol, conforme as três definições da Academia Real Espanhola, designa: 1) Distanciar, llevar a alguien o algo lejos o más lejos; 2) Ahuyentar, hacer huir.; 3) Apartar, rehuir, evitar ${ }^{14}$. Nas três possibilidades oferecidas pelo dicionário está compreendido o movimento de afastamento, uma fuga. Presumo que Alejandra tenha escutado o verbo dentro do próprio nome e respondido a ele. A explicação que me ocorre para a atitude de mudar a assinatura e pedir para ser chamada de Alejandra se relaciona menos com um retorno às origens etimológicas desse nome próprio grego que propriamente uma tradução intralinguística (como sugere Campos), uma apropriação livre e criativa desse significante no pleno propósito de fazer de com seu corpo o corpo do poema ${ }^{15}$. É dessa forma que estabeleço essa relação entre a apropriação do nome, que já era dela, como esforço notável de se ex-crever, de se valer da linguagem e fazê-la envergar para, nessa dobra, nomear o que não tem nome: sua singularidade.

Afinal, o que é um nome senão essa aporia do chamado, isto é, esse instante em que não se tem escolha senão responder a ele? Alejandra responde, pois, do seu jeito. Assim, rechaçar o nome Flora e se decidir por Alejandra é ser na dobra da linguagem, na disseminação irredutível do sentido. É, acredito, o ato de assumir, não uma identidade, mas a autoria pela escritura desse nome que carrega. É ser responsável pela nomeação que a precede e a que ela não pode escapar. Mas que pode, no entanto, colocar-se à escuta dessa ressonância que é o nome esvaziado de significados prontos para ser provisoriamente preenchido na aproximação de cadeias significantes atendendo ao movimento mesmo da disseminação que

\footnotetext{
${ }^{14}$ Real Academia Española. Acesso em: http://dle.rae.es/?id=1hWUthy

${ }^{15}$ Segundo Nancy (2000), "o corpo é o facto que se escreve, mas não é de modo algum onde se escreve, nem sequer aquilo que se escreve- mas sempre o que a escrita excreve" (p. 84). Um corpo, complementa Nancy, é o que, de uma escrita, não é para ler.
} 
singulariza a linguagem poética. Pedir para ser chamada pelo nome de Alejandra e passar a responder por ele faz parte desse projeto de escritura. Tal como entendo, é admitir ser aquela que se aleja, a que mora na distância, na errância para morte e que faz de seu corpo, de carne e osso, um gerúndio. Com isso, a poeta logra fazer dele também o corpo do poema que escreve. Pizarnik se entrega à experiência inalienável do testemunho das agruras desse seu caminhar absolutamente solitário e obstinado para morte. 0 nome a assombra e ela responde ao seu chamado portando-o, ainda que seja pelo enunciado que revela seu esgotamento:

Aun la voz es un síntoma de tu vacío. Aun el viento. Aun la más simple palabra. No hay ninguna fuerza para seguir portando el propio nombre. ¿Y qué? Ninguna fuerza para esperar que termine esta espera. Llega un día en que se sabe que se ha ido muy lejos dentro del espejo. ${ }^{16}$

Também o poema "Sólo un nombre" ${ }^{17}$ é a síntese dessa portabilidade que tento descrever:

\author{
alejandra alejandra \\ debajo estoy yo \\ alejandra
}

A forma de pirâmide invertida tem a base e o topo constituídos pelo nome próprio, o começo e o fim, ou o sem começo nem fim dado pelo assombro dessa repetição do nome fazendo com que os versos recaiam sobre si mesmos a queda infinita do abismo sobre o eu que nunca alcança. Os extremos se separam pelo verso do meio que situa o lugar do eu: debaixo de tudo. É o lugar da falta de lugar, conforme mencionei, da que não tem pátria, da viajante, da estrangeira, da "cantora noturna"18, da "filha do vento" ${ }^{19}$ que erra em direção ao fim, da que não cessa de se nomear e

\footnotetext{
16 PIZARNIK, 2012, p. 289.

17 Id., 2012a, p. 65.

18 Id., 2012a, p. 213.

19 Id., 2012 a, p. 76.
} 
que não é senão escombro desse nome acachapante que a leva como uma folha ao vento e que é preciso suportar. Alejandra cessa de viver para escrever, para testemunhar essa experiência de ir-se. É nesse sentido que sua hospitalidade é a sua morte, pois apenas ela, autora-testemunha, pode atestar sua experiência da errância, do despertencimento, da inadequação e da certeza da iminência da morte. No entanto, sobrevive a isso por meio da escrita: “¿Posibilidades de vivir? Sí, hay una. Es una hoja e blanco, es despeñarme sobre el papel, es salir fuera de mi misma y viajar en una hoja en blanco". 20

Aponto esses aspectos da biografia da autora que dizem respeito, sobretudo, ao nome e às línguas de Pizarnik porque, a meu ver, constituem elementos-chave $\mathrm{e}$ não disjuntivos para a leitura de sua escritura como testemunho de sua experiência singular que é a de viver em direção à morte como única alternativa à falta de alternativa que é estar no mundo:

Y pensó en sí misma y halló solamente confusión. Pero aun así sabía que era necesario escribir porque solo ella podría dar testimonio de algunas cosas por las que vivía. Aun cuando escribiera sobre los ruidos nocturnos, los vagidos de las cosas a medianoche y la tristeza de su ser intacto y no obstante definitivamente deteriorado, ella sabía que tenía que escribirlo. ${ }^{21}$

Nas fronteiras indecidíveis entre vida e literatura, um lugar de dizer e de escrever foi se delineando e tornando possível existir em meio à constatação da impossibilidade. Trata-se de um lugar que diz da própria impossibilidade de viver, da rejeição ao mundo tal como se lhe apresenta. Um lugar que não é propriamente o da morte, mas o de seu assombro, do assombro de quem inelutavelmente caminha para ela como única possibilidade de viver - e viver como isso que chamamos de normalidade e que consiste na implicação da pessoa no cotidiano, no trabalho, na burocracia, nos protocolos sociais, etc. Nesse sentido, Pizarnik se apropriou dos atravessamentos que constituíram sua singularidade e cevou para si um lugar de onde testemunhar essa experiência inalienável. É assim que existe na e para a literatura sabendo que é ela que a consome

${ }^{20}$ Id., 2012, p. 95.

${ }^{21}$ Id., 2012, p. 293. 
[...] sé de una manera visionaria, que moriré de poesía. Esto no lo comprendo perfectamente, es vago, es lejano, pero lo sé y lo aseguro. Tal vez ya sienta los síntomas iniciales: dolores donde se respira, sensación de estar perdiendo mucha sangre por alguna herida que no ubico. ${ }^{22}$

E também o que a possibilita viver: "Esta vez es certo: la salud está en la literatura. Es cierto pero también es abstracto"23.

Um testemunho, conforme Derrida ${ }^{24}$, só é testemunho se ele se deixa assombrar pela possibilidade de ficção, isto é, da literatura. Assim, o testemunho mora no limite do indecidível entre verdade e não-verdade, direito e não-direito, felicidade e perjúrio. Se testemunhar é tornar público um segredo, é também a própria impossibilidade de sua atestação na medida em que ninguém pode corroborar o que enuncia a testemunha: só ela teve a experiência do instante que relata. No entanto, esse relato, que não reitera a experiência mesma da testemunha, dialoga com as experiências singulares, por sua vez, de quem ouve ou lê um testemunho. É nessa medida que o testemunho é, ao mesmo tempo, singular e universalizante.

Afirmar que a testemunha guarda um segredo em seu testemunho quer dizer que por meio dele atesta a existência do segredo, mas não revela seu coração ${ }^{25}$. Para que se reconheça um testemunho, é preciso que, além de presenciar esse instante do segredo, a testemunha o ateste com um ato de fala endereçado a alguém a quem se supõe o domínio suficiente da língua ${ }^{26}$. 0 que a testemunha diz é: "é preciso acreditar em mim porque aí onde testemunho sou único, insubstituível" 27 . 0 dêitico "aí" é a marca do instante e do lugar, do aqui-agora que assegura a singularidade do testemunho e é desse ato de fala que, de acordo com Derrida, também deriva um "nós" indeterminado, que não pressupõe apoio ou consenso, mas a partilha do idioma, a corresponsabilidade da competência linguística.

Assim, a natureza do testemunho é a exemplaridade que decorre tanto de seu aspecto singular, quanto do universalizável. É singular porque implica um aqui-

\footnotetext{
${ }^{22}$ Id., 2012, p. 260.

${ }^{23}$ Id., 2012, p. 269.

24 DERRIDA, 2004.

25 Id., 2004, p. 25-26.

${ }^{26}$ Id., 2004, p. 31.

${ }^{27}$ Id., 2004, p. 38.
} 
agora não comutável: ninguém testemunha pela testemunha, porque ninguém pode repetir a sua experiência interna e externa no tempo e no espaço. No entanto, é universalizável como iterabilidade protética que se presta à possibilidade da ficção e da mentira, do simulacro e da literatura. Em síntese, a condição testemunhal é a de que o singular seja universalizável. Logo, se tomo a escritura de Pizarnik como testemunho é porque, como leitora, hospedo-me no seu texto mesmo sem conhecer o seu segredo e ele me serve de abrigo dizendo algo a respeito de minha condição. Pizarnik é consciente dessa exemplaridade de sua escritura e a atesta ao comentar, na entrada de seu diário do dia 30 de dezembro de 1962, o que uma amiga lhe contara durante horas sobre o impacto que um de seus poemas provocara nela:

me dijo que se sintió mejor, que mi poema fue como un bálsamo para ella. $Y$ yo pensé que tal vez la poesía sirve para esto, para que en una noche lluviosa y helada alguien vea escrito en unas líneas su confusión inenerrable y su dolor. ${ }^{28}$

Assim que, seguindo ainda o pensamento derridiano, o testemunho é questão de instante e de instância "em mais de uma língua porque se ele é audível desde o limiar da singularidade mais idiomática, mais intraduzível, esse apelo à universalização é um apelo à tradução" ${ }^{29}$. A tradução a que o filósofo se refere como traduzibilidade inerente ao testemunho não se confunde com desfazer seu caráter idiomático, mas na operação do texto que fará comparecer as nuances da letra em qualquer idioma.

Acredito que seja nesse ponto o momento para comentar a ideia de que Pizarnik se vale de uma terceira língua para além do espanhol e do yiddich, ou melhor, fazendo dessas duas a sua própria língua literária: "para transcender el lenguaje debo antes hacerlo mío" ${ }^{30}$. Assim como assume o nome que exige dela o testemunho da experiência do morrer na desconjuntura da poesia, os idiomas que a atravessam também concorrem para a experiência abismal nesse tempo desconjuntado em que Pizarnik escreve e sobrevive. Uma terceira língua para a qual

\footnotetext{
28 PIZARNIK, 2012, p. 302.

${ }^{29}$ DERRIDA, 2004, p. 40.

${ }^{30}$ Id., 2012, p. 101.
} 
a poeta traduz seu testemunho é a sua sintaxe poética própria, seu espanhol fragmentado e repleto de imagens que criam o abismo ao mesmo tempo em que se abismam nessa torção do idioma que não é o seu, que não é a língua de sua mãe, mas é a língua materna revirada pela língua de sua mãe, o yiddich.

A língua de seus pais é a língua sagrada que porta, não apenas o segredo do sagrado, mas com ele a promessa de mantê-lo e a possibilidade do perjúrio ${ }^{31}$. Essa disjunção é uma ferida aberta em Pizarnik e podemos vê-la na pele de sua escritura, da camada mais superficial ao tutano de seus ossos que lhe doem quando acorda e se dá conta da inadequação de estar no mundo. Quando ela afirma em seu diário que não sabe o espanhol, que não maneja bem os verbos, que é incapaz de escrever um romance, porque é impossível se apoderar da linguagem, quando dorme pensando em se matar e acorda cantando uma canção judia, quando pensa em escrever em francês como alternativa ao seu alheamento em relação ao espanhol (para ela, um enxerto estranhamente latino), quando inventa uma língua que lhe é própria dentro dessa outra que seu corpo rejeita porque (não) reconhece.

No entanto, a literatura também é uma palavra latina. Pronunciar essa palavra e ser compreendido pelo outro, a despeito da diversidade do idioma materno, implica, segundo Derrida, "na hospitalidade constrangedora ou no acolhimento violento de uma latinidade" ${ }^{32}$. Isso está posto pelo filósofo no sentido de que tudo o que não se deixe ser traduzido ou acolhido, o que precede ou excede a história da latinidade não é admitido como literatura. Derrida aperta o dedo na ferida do etnocentrismo literário e cultural questionando se, para além da latinidade dessa instituição moderna de literatura - que extrapola a cristandade como Igreja Romana, o direito romano e o conceito romano de Estado, haveria algum sentido literal da palavra em questão, isto é, uma institucionalização e um direito a ela fora da cultura latino-romano-cristã. Ou ainda, em sentido mais geral, se haveria uma literatura instituída e um direito a ela não europeus.

Acerca do etnocentrismo latino literário denunciado por Derrida, Antoine Berman já afirmara que a cultura romana é uma cultura-da-tradução na medida em que após o período em que os latinos liam em grego, sucedeu um período em que

31 DERRIDA, 2010.

${ }^{32}$ Id., 2004, p. 14. 
todo o corpus de textos gregos foi traduzido. Foi precisamente esse processo de tradução massiva que fundou a literatura latina. Todavia, tratou-se da tradução etnocêntrica que procedeu pela "anexação dos textos, das formas e dos termos gregos"33 que se tornaram irreconhecíveis na mixórdia dos idiomas. Segundo o teórico, essa prática tradutória corrobora para a acepção de tradução que se tornou canônica no Ocidente, a qual se apropria da língua traduzida e avoca à tradução o "direito de vencedor". Além disso, Berman denuncia o ímpeto tradutório da romanidade que visou:

constituir sua própria cultura por pilhagem, empréstimos e anexação, superpõe-se o impulso evangelizador do cristianismo: é necessário que cada povo possa entender a Palavra de Deus, é necessário traduzir. É a tradução para..., mais do que a tradução por..., [...] na Antiguidade o impulso evangelizador unia-se ao impulso anexionista romano. ${ }^{34}$

Ao remontar às raízes antigas dessa acepção etnocêntrica de tradução, que se faz pelo saque do conhecimento alheio e pelo apagamento de suas marcas, Berman entende que o procedimento se baseia em instância ainda mais distante que as conquistas romanas. 0 filósofo enxerga uma origem na cesura platônica que considera o sentido como 'um ser em si', como pura idealidade que a tradução transfere de uma língua para outra deixando para trás seu corpo, sua materialidade. Por trás dessa compreensão estaria ainda a noção de um logos comum e universal que funda a tradução para além das diferenças. Perora ainda que a "fidelidade ao sentido é a infidelidade à letra" ${ }^{35}$, o que implica que partir do princípio de que é possível captar o sentido menosprezando sua letra, seu corpo mortal, sua casca terrestre é, antes de tudo, uma atitude etnocêntrica. A anexação de uma língua pressupõe a submissão da obra estrangeira à "língua de chegada" ${ }^{36}$, que é considerada mais absoluta, mais ideal e mais racional.

Berman, entretanto, fundamenta sua teoria da tradução pela letra sobre a ética da singularidade irredutível que muito provavelmente foi lido por Derrida

\footnotetext{
33 BERMAN, 2007, p. 30.

34 Ibid., p. 31.

35 Ibid., p. 32.

${ }^{36}$ Ibid.,p. 33.
} 
como aquela pretensão de tradução do testemunho que não o exime de ser idiomático. Traduzir a letra é traduzir mantendo a aporia, o estranhamento que não apaga a marca da língua do outro, ao contrário, o hospeda. Disso também sabia Pizarnik desde pequena que, ainda que intuitivamente, já traduzia a si mesma pela letra pondo-se a completar "con palabras inventadas, con un idioma imaginario" a frase "Sí, pero lo que yo quería decirles es que..."37. Procedendo desde muito cedo com esse exercício de inventar significantes, Pizarnik aprende ainda a ler cada palavra, incluindo as preposições, isoladamente, "como si estuviera haciendo una autopsia"38.

Ao ler a frase de Pizarnik que afirma que sua escritura é uma escritura da tradução, não obstante tomá-la como um testemunho, cotejo sua arte com essa noção de literatura etnocêntrica e esboço o primeiro princípio que deverá nortear a minha proposta de tradução para sua escritura. Se sua poesia é tradução, o que ela traduz é a experiência da "lejanía" a partir de línguas que fala, mas que não são suas propriamente: o espanhol (sua língua materna e latina) e o yiddich (língua de sua mãe, de seus pais, na verdade, à margem da latinidade ocidental e sagrada).

Não ter uma língua que seja sua, única e sem opacidade, é o mesmo de não ter uma pátria, de não ter um nome, não ter um rosto adequado ao mundo inadequado. Sobreviver, para Alejandra Pizarnik, equivale então a fazer de sua língua literária o próprio albergue do longínquo, o estrangeiro em seu próprio corpo. Abrigar não é rechaçar as outras línguas de que se vale, ou que lhe restam, mas conduzir a letra ao limite, promovendo a abertura do sentido, fazendo com despenque sobre si mesma. Em sua tradução, o sentido estrangeiro não é aclimatado, não brota como um fruto de nenhuma de suas línguas, ele é desconjuntado e ex-tranho, tanto em sua escrita quanto em sua fala idiossincrática e inclassificável. É assim que faz com seu corpo o corpo do poema, com sua estrangeiridade - que não é em relação a este ou aquele país, tradição, cultura, valores, modos de ser, ou língua - mas a uma estrangeiridade em relação a si mesma e ao projeto humano de habitar o mundo.

\footnotetext{
37 PIZARNIK, 2012, p. 286.
}

38 Ibid., p. 286. 
Pizarnik materializa com seu corpo e sua literatura o inominável distanciamento da outridão, da irredutível alteridade desse outro que está, aprioristicamente, dentro e fora, diante do eu. Sua poesia é essa aporia. Sua vida é essa aporia. A indecidibilidade é a marca dessa vida que não pode senão ser esse albergue do longínquo, que leva ética da tradução às últimas consequências, se preciso ao sacrifício de seu corpo, e, ao mesmo tempo, está diante da escolha incontornável por fazê-lo. Sobreviver, para Pizarnik, é uma questão ética. Ela ouve o chamado de seu nome e vai, obedece a essa ordem que a antecede ontologicamente de relatar o testemunho singular do que é ser Alejandra.

A exemplo de Abraão, que se volta a Deus prontificando-se: "eis-me aqui", o testemunho da poeta consiste nessa aporia que suspende a escolha de responder ou não ao chamado de seu nome para relatar seu segredo sem revelá-lo. Ao comentar o episódio da escolha abraâmica, Alejandra pondera:

Aunque tal vez, lo que pasó es que Abraham, simplemente, amaba más a Dios que a su hijo y a su raza. Tal vez ni siquiera eligió. Estaba enamorado de Dios y por ello no Le pareció excesivo matar a su hijo. (De quién estoy hablando. $)^{39}$

Pizarnik passa dessa reflexão a uma questão material sobre sua pena e retoma em seguida: "Los instantes suspendidos. Los actos fuera del tempo.", como se ainda ponderasse sobre o gesto irrevogável de Abraão com a mão suspensa sobre seu primogênito, dando-lhe a morte em nome de Deus. 0 sacrifício de Isaac, que mesmo sem haver morrido foi morto pelas mãos do pai, é o segredo, a aliança com Deus que Abraão deverá suportar solitariamente, sem compartilhar com ninguém. Pizarnik então retoma as questões sobre a própria escrita e emenda, por fim: "El terror de no contar con un testigo a quien referirle las penas y las alegrías". 0 que a poeta lamenta, ao cabo, é que ninguém testemunha pela testemunha40. Seja para aquele que dá o filho em sacrifício, ou aquela que se oferece em sacrifício de corpo e testemunho com sua escritura, é da singularidade do acontecimento que ambos suportem em silêncio o assombro do nome.

${ }^{39}$ Ibid., p. 387.

40 DERRIDA, 2003. 
Enfim, entendo, por ora, que se pretendo analisar e traduzir a obra dessa poeta, devo admitir que ela se fez no seio de uma tradição judaico-cristã que, primeiramente, não é a mesma da minha, e que se distingue de mim, entre tantos motivos, por se tratar de uma cultura da errância, do deserto, do êxodo. É essa, portanto, a lente pela qual acredito ser possível ler e traduzir Alejandra: a da não identificação, da preservação de sua singularidade em minha leitura de seu testemunho. Um testemunho que, conforme afirmei, consiste na aporia de escolher sem haver escolha, de portar um segredo (que é o seu próprio sacrifício em nome de seu testemunho) que ela conta sem revelar, de atender ao chamado de seu nome sem questionar. Tudo isso muito atravessado pela diferença entre as línguas e consequentemente pelas culturas que a constituem. Ainda não é muito o que sei sobre a escritura dessa portenha judia, mas já posso afirmar que reduzir qualquer gesto de Alejandra à ingenuidade e à infantilidade de uma pessoa que se recusou a crescer e a se adequar ao mundo adulto, é matá-la outra vez. É aniquilar sua singularidade absoluta, pelo apagamento de sua alteridade com a violência da identificação. 0 compromisso que assumo com sua letra guarda semelhança, no entanto, com seu modo de traduzir o impossível no sentido de pretender ser um abrigo ao seu longínquo sem querer reduzir a distância que o ilumina e distingue.

\section{Referências}

BERMAN. Antoine. A tradução e a letra ou o albergue do longínquo. PGET/7Letras, UFSC. 2007.

CAMPOS. Haroldo de. A operação do texto. São Paulo: Perspectiva, 1976.

\section{O sequestro do Barroco na formação da literatura}

brasileira: o caso Gregório de Matos. São Paulo: Iluminuras, 2011.

DERRIDA, Jacques. Carneiros. 0 diálogo ininterrupto: entre dois infinitos, o poema. Trad. Fernanda Bernardo. Coimbra: Palimage, 2003. 
Morada. Maurice Blanchot. Trad. Silvina Rodrigues

Lopes. Lisboa: Vendaval, 2004.

O animal que logo sou. Trad. Fábio Landa. 2.ed. São

Paulo: Editora Unesp, 2011.

Los ojos de la lengua. Traducción: Jazmín Acosta.

Publicada enNombres. Revista de Filosofía, Córdoba, año XIX, nº 24, Noviembre de 2010.

Disponível

em:

http://redaprenderycambiar.com.ar/derrida/textos/textos.htm. Acesso em: 11 de novembro de 2016.

DUQUE-ESTRADA. Elizabeth Muylaert. Nas entrelinhas do talvez. Derrida e a literatura. Rio de Janeiro: Ed. PUC-Rio: Ed. Via Verita, 2014.

NANCY, Jean-Luc. Corpus. Trad. Tomás Maia. Lisboa: Vega. 2000.

PIÑA, Cristina. Alejandra Pizarnik: uma biografia. Buenos Aires: Ediciones Corregidor, 2005.

PIZARNIK, Alejandra. Diarios - Alejandra Pizarnik. Argentina, Buenos Aires: Lumen, 2012.

Poesía completa. Argentina, Buenos Aires: Editorial Lumen, 2012a.

SMITH, Barbara. Poetry as fiction. New Literary History, v. 2, n. 2. Baltimore, Maryland: Johns Hopkins University Press, 1971, p. 259-281. 
Fernanda Ribeiro Marra é doutoranda em Teoria Literária pelo Programa de PósGraduação em Literatura da Universidade de Brasília - UnB.

Recebido em: 17/02/2017 Aprovado em: 10/04/2017 Publicado em junho de 2017 